\title{
Cross-reactivity of the CEDIA buprenorphine assay in drugs-of-abuse screening: influence of dose and metabolites of opioids
}

This article was published in the following Dove Press journal:

Substance Abuse and Rehabilitation

28 October 2015

Number of times this article has been viewed

\section{Jon Andsnes Berg' \\ Jan Schjøtt ${ }^{1,2}$ \\ Kjell O Fossan' \\ Bettina Riedel ${ }^{1,2}$}

'Section of Clinical Pharmacology, Laboratory of Clinical Biochemistry, Haukeland University Hospital, ${ }^{2}$ Faculty of Medicine and Dentistry, Department of Clinical Science, University of Bergen, Bergen, Norway
Purpose: The cloned enzyme donor immunoassay (CEDIA) for buprenorphine is applied for both urine drugs-of-abuse screening and compliance monitoring. Sensitivity, specificity, and optimal cutoff of this assay have differed between studies. This may indicate that cross-reactivity has to be taken into account during assay evaluation. We therefore investigated the performance of the CEDIA buprenorphine assay for use in our patient population and explored the impact of cross-reactivity on assay accuracy.

Methods: The CEDIA buprenorphine assay and high-performance liquid chromatographytandem mass spectrometry were employed to analyze drugs-of-abuse in urine samples from a healthy drug-naïve male volunteer after intake of two tablets of a prescription drug containing $400 \mathrm{mg}$ paracetamol +30 mg codeine phosphate, and in urine samples $(n=2,272)$ from drugaddicted patients. Receiver operating characteristic analyses were performed to express the diagnostic accuracy of the CEDIA buprenorphine assay.

Results: CEDIA buprenorphine was positive in one urine sample from the drug-naïve person after intake of the prescription drug. Twenty-five (1.1\%) of the patient urine samples were positive for buprenorphine by CEDIA, but negative by high-performance liquid chromatography-tandem mass spectrometry. Codeine, morphine, and their respective metabolites were prevalent in samples that were false positive for buprenorphine. The specificity of the CEDIA buprenorphine assay increased to $99.7 \%$ when the cutoff was increased from $5 \mathrm{ng} / \mathrm{mL}$ to $10 \mathrm{ng} / \mathrm{mL}$.

Conclusion: Intake of a therapeutic dose of codeine can yield a false-positive CEDIA buprenorphine result. Additive effects from metabolites of codeine contribute to cross-reactivity in concentrations much lower than listed in the manufacturer's cross-reactivity guide. Raising the cutoff from $5 \mathrm{ng} / \mathrm{mL}$ to $10 \mathrm{ng} / \mathrm{mL}$ increased the diagnostic accuracy. Clinicians should be informed about the risk of false-positive results with the CEDIA buprenorphine assay.

Keywords: buprenorphine, codeine, cross-reactivity, urine drugs-of-abuse screening, immunoassay

\section{Introduction}

Buprenorphine is a partial agonist/antagonist on the opioid receptors and may be prescribed both as an analgetic and in medication-assisted rehabilitation (MAR) of opioid-dependent patients. ${ }^{1}$ Buprenorphine was reported as the third most prevalent misused opioid, next to heroin and methadone. ${ }^{2}$ Although it seems to be more frequently misused in Europe and Asia than in the US, ${ }^{3}$ a $384 \%$ increase of misuse has been reported between 2006 and 2011 in the US. ${ }^{4}$ Thus, urine drug screening of buprenorphine is used to monitor compliance in MAR and side abuse. ${ }^{5}$

Chromatographic methods with mass spectrometry have high diagnostic accuracy but are time consuming and resource demanding. ${ }^{6}$ Immunochemical methods may be
Correspondence: Jon Andsnes Berg Section of Clinical Pharmacology, Laboratory of Clinical Biochemistry, Haukeland University Hospital, Jonas Lies vei 65, 502I Bergen, Norway Tel +475597 7852

Email jon.andsnes.berg@helse-bergen.no 
preferential because they do not require the same degree of training and competence among laboratory staff and because they have a fast response time. ${ }^{7}$

Cross-reactivity leading to false-positive results is a known problem when using immunochemical methods. ${ }^{8}$ The producer of the cloned enzyme donor immunoassays (CEDIAs) has published a cross-reactivity guide ${ }^{9}$ that presents an overview over compounds that gave false-positive results in samples spiked with the potential cross-reactant over a range of clinically achievable concentrations. However, cross-reactivity with metabolites was not fully evaluated. Furthermore, in a clinical setting, several structurally related substances may be present simultaneously in urine samples from addicted patients, which may increase the potential of unintended analytical interference. The CEDIA buprenorphine assay has been associated with cross-reactivity with various substances, especially structurally related opioids such as morphine and codeine..$^{5,10,11}$ Both sensitivity and specificity have differed between studies of this assay, even though a cutoff of $5 \mathrm{ng} / \mathrm{mL}$ was applied in all. ${ }^{5,10,12}$ Typically in these cases, the signal in the false-positive samples has been only slightly above the manufacturer's recommended $5 \mathrm{ng} / \mathrm{mL}$ cutoff concentration. Hence, the choice of an appropriate cutoff is of particular relevance for the performance of the CEDIA buprenorphine assay in a given population.

The urine drugs-of-abuse screening panel in our laboratory is used in a therapeutic setting and covers commonly abused drugs such as amphetamines, benzodiazepines, and opioids, including methadone and buprenorphine, which are of particular relevance to patients included in MAR. Positive buprenorphine screening results, indicating buprenorphine abuse in patients not treated with buprenorphine, could trigger a tighter therapeutic control or imply more serious consequences, such as exclusion from institutional therapy or loss of social benefits. This underlines that analytical specificity is of greater therapeutic significance than sensitivity. We regularly receive inquiries from clinicians questioning positive CEDIA buprenorphine results.

We therefore examined cross-reactivity by comparing the results obtained by CEDIA with those acquired by highperformance liquid chromatography-tandem mass spectrometry (HPLC-MS/MS). We first examined whether intake of a therapeutically recommended dose of a codeine preparation could yield false-positive CEDIA buprenorphine results. We then investigated which cutoff concentration would render the best diagnostic accuracy in a population associated with drug abuse.

\section{Methods}

\section{Sample materials}

The study material included anonymous, retrospective data used for quality control purposes in our department. The case study included only one of the authors (JS), and involved no patients. Thus, the study did not need formal approval or registration as a clinical trial according to the guidelines of the Regional Committee for Medical and Health Research Ethics and the Norwegian Data Protection Officer for Research at the Haukeland University Hospital. Furthermore, no patient consent was necessary.

In the case study, one healthy drug-naïve male volunteer (JS) was given two tablets of Paralgin Forte ${ }^{\circledR}$ (codeine phosphate $30 \mathrm{mg} /$ paracetamol $400 \mathrm{mg}$ ). Sixteen urine samples, including one sample collected before administration of the drug, were collected from the volunteer during the following 55 hours. The samples were analyzed for buprenorphine with the CEDIA assay and for opioids and metabolites, including codeine with HPLC-MS/MS.

In the performance study, 2,272 urine samples that had been sent to the laboratory at the Haukeland University Hospital for drugs-of-abuse screening during a 4-week period were analyzed with both CEDIA and HPLC-MS/MS. Samples were taken from patients treated with either buprenorphine or methadone in specialized MAR clinics and from patients in general practices, psychiatric wards, outpatient clinics, emergency units, and other treatment institutions for drug addiction. Based on the information given on the requisition forms, $43 \%(n=996)$ of the patients were MAR patients. Due to the possibility of cross-reactivity in the immunochemical methods, all samples were analyzed for the complete drugsof-abuse panel available at our laboratory, regardless of which analyses that had been required.

\section{Analytical methods}

All urine samples were tested for specimen validity tests including creatinine and $\mathrm{pH}$ before parallel analysis of CEDIA and HPLC-MS/MS. Urine samples with creatinine concentrations $>2.3 \mathrm{mg} / \mathrm{dL}$ and with $\mathrm{pH}$ between 4.5 and 8.0 were considered valid.

The CEDIA buprenorphine assay was performed on AU-680 (Beckman Coulter Biomedical Limited, Brea, CA, USA), and the reagents were supplied by ThermoFischer Scientific (Waltham, MA, USA). The assay was performed semiquantitatively using calibrators for buprenorphine containing $0 \mathrm{ng} / \mathrm{mL}, 5 \mathrm{ng} / \mathrm{mL}, 20 \mathrm{ng} / \mathrm{mL}$, and $50 \mathrm{ng} / \mathrm{mL}$. According to the manufacturer's recommendation, we employed a cutoff concentration of $5 \mathrm{ng} / \mathrm{mL}$ for buprenorphine. The total analytical imprecision was 
$<9 \%$ at the manufacturer's recommended cutoff concentration. Total analytical imprecision was calculated using one measurement per day for 30 days. Imprecision measurement for CEDIA buprenorphine was performed with CEDIA buprenorphine, low and high controls, and with drugs of abuse (DOA) total level 4. All control materials were supplied by Thermo-Fischer Scientific. The CEDIA buprenorphine assay is reported to have cross-reactivity of $100 \%$ for buprenorphine and for buprenorphine-3glucuronide, but no cross-reactivity for norbuprenorphine or norbuprenorphine-3-glucuronide. ${ }^{9}$ Performance of the CEDIA buprenorphine assay was investigated by comparison with HPLC-MS/MS. The samples were prepared using a Hamilton AT2plus (Hamilton Robotics GmbH, Martinsried, Germany) and analyzed on an API 2000 (AB Sciex, Stockholm, Sweden) with a TurboIonSpray-ionization source and an 1100-series HPLC-system (Agilent Technologies, Waldbronn, Germany). Separation was achieved using a Supelco Ascentis Phenyl, $2.1 \mathrm{~mm} \times 50 \mathrm{~mm}, 3 \mu \mathrm{m}$ analytical column maintained at $30^{\circ} \mathrm{C}$ (Sigma-Aldrich, St Louis, MO, USA) using gradient elution with $0.1 \%$ formic acid in water and acetonitrile as mobile phases. The sample preparation consisted of a twofold dilution with eleven deuterated internal standards and $0.1 \%$ formic acid in water. No preanalytical hydrolysis was performed. Only one multiple reaction monitoring-transition per analyte was monitored. However, both the parent drug and at least one metabolite were monitored. This was done because some analytes showed limited fragmentation and the presence of metabolites confirms intake of a specific drug. The limit of detection for buprenorphine, buprenorphine-glucuronide, norbuprenorphine, and norbuprenorphine-glucuronide was $0.9 \mathrm{ng} / \mathrm{mL}, 1.8 \mathrm{ng} / \mathrm{mL}$, $1.9 \mathrm{ng} / \mathrm{mL}$, and $2.4 \mathrm{ng} / \mathrm{mL}$, respectively. Total analytical imprecision at $10 \mathrm{ng} / \mathrm{mL}$ was $14.7 \%, 18.6 \%, 32.9 \%$, and $29.8 \%$ for buprenorphine, buprenorphine-glucuronide, norbuprenorphine, and norbuprenorphine-glucuronide, respectively. The method also included analyzes of codeine and morphine and its metabolites, other opioids, and other drugs-of-abuse. Analytical performance data for these analytes as measured by HPLC-MS/MS is given in Table S1.

In order to increase specificity, total buprenorphine, norbuprenorphine, and benzodiazepines were additionally analyzed with a different HPLC-MS/MS method, which involved enzymatic hydrolysis. The sample preparation consisted of a twofold dilution with $\beta$-glucuronidase (5,000 units/ $\mathrm{mL}$ urine) from Escherichia coli (G7396, Sigma-Aldrich), eight deuterated internal standards and BIS-TRIS-propane buffer ( $\mathrm{pH}$ 6.8). The samples were then incubated at $37^{\circ} \mathrm{C}$ for 2 hours. The hydrolysis was stopped by ultrafiltration using a $10 \mathrm{kD}$ membrane filter plate (MultiScreen Ultracel-10; Merck Millipore, Billerica, MA, USA). Two multiple reaction monitoring-transitions per analyte were monitored with set criteria for relative intensity, which gives identification points considered to provide reliable analyte identification. ${ }^{13}$ The acceptance criteria for quantifier and qualifier ions were a signal-to-noise ratio of $\geq 10$ and $\geq 3$, respectively. The efficiency of the hydrolysis step for buprenorphineglucuronide was evaluated in each sample by comparing the results of the two HPLC-MS/MS methods.

Validation included linearity of the method, limits of detection and quantification, imprecision and accuracy, matrix effect, carryover, hydrolysis efficiency, chromatographic interferences, and stability of processed samples. Quality control of the HPLC-MS/MS methods was performed using home-made spiked urine control material. Duplicate quality controls with two concentration levels were included in every series. The methods are part of the Labquality's EQA (external quality assessment) program for drug abuse screening in urine and LGC Standards drugs of abuse in urine PT (proficiency testing) scheme.

Cross-reactivity of codeine-6-glucuronide (C6G) in the CEDIA buprenorphine assay was tested with spiked aliquots of the same negative urine sample pool from three healthy volunteers. The $\mathrm{C} 6 \mathrm{G}$ analytical reference standard was supplied by Lipomed AG (Arlesheim, Switzerland). The aliquots were spiked with different amounts of $\mathrm{C} 6 \mathrm{G}$ giving $\mathrm{C} 6 \mathrm{G}$ concentrations of $10,000 \mathrm{ng} / \mathrm{mL}, 20,000 \mathrm{ng} / \mathrm{mL}, 30,000 \mathrm{ng} /$ $\mathrm{mL}$, and $40,000 \mathrm{ng} / \mathrm{mL}$, before they were analyzed with the CEDIA buprenorphine assay.

\section{Statistical analysis}

In the patient samples, we defined true-positive results to be positive with both HPLC-MS/MS and CEDIA. True negative results were negative with both HPLC-MS/MS and CEDIA. False-positive samples were positive with CEDIA, but negative with HPLC-MS/MS, whereas false-negative samples were negative with CEDIA, but positive with HPLC-MS/ MS. From these results, we calculated sensitivity, specificity, positive predictive value (PPV), negative predictive value (NPV), and accuracy using Bayesian analysis..$^{14}$ To find the most favorable CEDIA cutoff for buprenorphine in terms of highest specificity and sensitivity, we performed a receiver operating characteristic (ROC) analysis using Analyse-it (Analyse-it Software, Ltd, Leeds, UK). SPSS 20.0 (IBM Corporation, Armonk, NY, USA) was otherwise used to analyze the data. Pearson product moment correlation was used to analyze the relationship between C6G and CEDIA buprenorphine. 


\section{Results}

\section{Case study}

CEDIA buprenorphine assay yielded a positive result above the recommended cutoff concentration at $5 \mathrm{ng} / \mathrm{mL}$ in the first out of 15 urine samples collected 5 hours after a single administration of $60 \mathrm{mg}$ of codeine phosphate and $800 \mathrm{mg}$ of paracetamol (Table 1). The concentration of codeine, norcodeine, and C6G in that specific sample was $2,550 \mathrm{ng} / \mathrm{mL}$, $490 \mathrm{ng} / \mathrm{mL}$, and $38,467 \mathrm{ng} / \mathrm{mL}$, respectively, as determined by HPLC-MS/MS. The creatinine concentration was $11.2 \mathrm{mg} / \mathrm{dL}$. Response in the CEDIA buprenorphine assay was observed over 15 hours after administration, but it was below cutoff of $5 \mathrm{ng} / \mathrm{mL}$ in all other samples but the first. No other drugs-of-abuse were detected with HPLC-MS/MS. In all samples, creatinine concentrations were between $2.3 \mathrm{mg} /$ $\mathrm{dL}$ and $18.6 \mathrm{mg} / \mathrm{dL}$, and $\mathrm{pH}$ was between 5.6 and 6.7 .

The relationship between $\mathrm{C} 6 \mathrm{G}$ concentrations and the signal in the CEDIA buprenorphine assay was linear (correlation coefficient $=0.998$ ) in negative urine samples spiked with C6G. A concentration of $40,000 \mathrm{ng} / \mathrm{mL}$ yielded a signal corresponding to $6.2 \mathrm{ng} / \mathrm{mL}$ in the CEDIA buprenorphine assay.

\section{Performance study}

Table 2 shows the distribution of the most frequently detected drugs in 2,272 patient urine samples. Almost half of the samples contained benzodiazepines, and clonazepam, and oxazepam were detected most frequently. Opioids other than methadone and buprenorphine were detected less frequently. Almost 5.4\% of the samples were positive for morphine and $2.5 \%$ for codeine. CEDIA rendered no false-negative results for buprenorphine, and the NPV was one in the 2,272 patient samples. Twenty-five urine samples $(1.1 \%)$ had a positive buprenorphine result with the CEDIA assay in concentrations ranging from $5.00 \mathrm{ng} / \mathrm{mL}$ to $18.20 \mathrm{ng} / \mathrm{mL}$, but no buprenorphine or metabolites detected by HPLC-MS/MS. Eighteen of these samples (72\%) were positive for both codeine and morphine-3-glucuronide (M3G) in a concentration range of 1,018-13,561 $\mathrm{ng} / \mathrm{mL}$, and 784-178,586 $\mathrm{ng} / \mathrm{mL}$, respectively (Table 3). Sixteen of these samples were also positive for morphine $(17-37,665 \mathrm{ng} / \mathrm{mL})$, and eleven for methadone (519-52,592 ng/mL). Five other samples were positive for methadone $(9,446-41,866 \mathrm{ng} / \mathrm{mL})$, either in addition to other drugs, such as oxazepam, delta-9-tetrahydrocannabinol, and zopiclone $(\mathrm{n}=3)$, or alone $(\mathrm{n}=2)$. One sample contained only oxazepam at a very low concentration, and in one other sample, no drugs or their metabolites were detected with our HPLC-MS/MS method. Taken together, the prevalence of false-positive urine samples for buprenorphine with the CEDIA assay was $1.1 \%$, the sensitivity was $100 \%$, the specificity was $98.0 \%$, and the PPV was 0.957 . In these 25 samples, the lowest creatinine concentration was $3.9 \mathrm{mg} / \mathrm{dL}$, the highest $50.4 \mathrm{mg} / \mathrm{dL}$, and $\mathrm{pH}$ was between 5.4 and 7.6.

An increase in the cutoff concentration of the CEDIA buprenorphine assay would reduce the number of false-positive results but would render an increase in the number of

Table I Results from urine samples $(\mathrm{n}=\mathrm{I5})$ after ingestion of two tablets of a prescription drug containing $400 \mathrm{mg}$ paracetamol $+30 \mathrm{mg}$ codeine phosphate by a healthy drug-naïve male volunteer

\begin{tabular}{|c|c|c|c|c|c|c|c|}
\hline \multirow[t]{2}{*}{ Time $^{a}$} & \multirow{2}{*}{$\frac{\text { CEDIA (ng/mL) }}{\text { Buprenorphine }}$} & \multicolumn{6}{|c|}{ HPLC-MS/MS (ng/mL) } \\
\hline & & C6G & Codeine & Norcodeine & Morphine & M3G & M6G \\
\hline 05.00 & 6.9 & 38,467 & 2,550 & 490 & 150 & 6,090 & 1,510 \\
\hline 07.00 & 2.4 & 11,079 & 390 & 110 & 30 & $\mathrm{I}, 500$ & 290 \\
\hline 09.00 & 2.9 & 17,308 & 490 & 180 & 30 & 2,320 & 480 \\
\hline 10.00 & 1.3 & 5,183 & 150 & 60 & 0 & 620 & 130 \\
\hline 14.00 & 1.4 & 7,275 & 290 & 100 & 50 & 2,220 & 460 \\
\hline 15.00 & 0.5 & 4,665 & 240 & 70 & 50 & 2,850 & 490 \\
\hline 22.25 & 0.2 & 3,371 & 130 & 60 & 50 & 2,070 & 330 \\
\hline 27.00 & 0 & 775 & 30 & 0 & 30 & 1,060 & 250 \\
\hline 30.00 & 0.1 & 0 & 0 & 0 & 0 & 610 & 120 \\
\hline 34.25 & 0 & 0 & 0 & 0 & 20 & 860 & 160 \\
\hline 39.00 & 0 & 0 & 0 & 0 & 0 & 800 & 160 \\
\hline 46.25 & 0 & 0 & 0 & 0 & 10 & 550 & 110 \\
\hline 50.34 & 0.1 & 0 & 0 & 0 & 0 & 300 & 0 \\
\hline 51.55 & 0.2 & 0 & 0 & 0 & 0 & 0 & 0 \\
\hline 55.00 & 0 & 0 & 0 & 0 & 0 & 0 & 0 \\
\hline
\end{tabular}

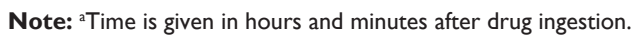

Abbreviations: CEDIA, cloned enzyme donor immunoassay; HPLC-MS/MS, high-performance liquid chromatography-tandem mass spectrometry; C6G, codeine-6glucuronide; M3G, morphine-3-glucuronide; M6G, morphine-6-glucuronide. 
Table 2 Frequency and share of positive results for drugsof-abuse in patient urine samples $(n=2,272)$, as determined by screening with HPLC-MS/MS

\begin{tabular}{lll}
\hline Substance & \multicolumn{2}{l}{ Positive results } \\
\cline { 2 - 3 } & $\mathbf{n}$ & $\%$ \\
\hline 6-Monoacetylmorphine & 34 & 1.5 \\
Amphetamine & 258 & 11.4 \\
Benzodiazepines & 959 & 42.2 \\
Buprenorphine & 711 & 31.3 \\
Codeine & 56 & 2.5 \\
Methadone & 664 & 29.2 \\
Methamphetamine & 320 & 14.1 \\
Morphine & 123 & 5.4 \\
\hline
\end{tabular}

Abbreviation: HPLC-MS/MS, high-performance liquid chromatography-tandem mass spectrometry.

false-negative results instead. In a ROC curve for the buprenorphine assay, the area under the curve was approaching 1, which indicated a very good diagnostic accuracy. Figure 1 shows PPV and NPV for CEDIA buprenorphine cutoff concentrations, ranging from $0 \mathrm{ng} / \mathrm{mL}$ to $49 \mathrm{ng} / \mathrm{mL}$. The ROC analysis indicated that a cutoff concentration of $11.2 \mathrm{ng} / \mathrm{mL}$ would give the best accuracy, with four false-positive and two false-negative results, giving a PPV of 0.994 and a NPV of
0.999. A cutoff concentration of $8.2 \mathrm{ng} / \mathrm{mL}$ would render no false-negative, but ten false-positive results.

\section{Discussion Principal findings}

A single intake of a recommended therapeutic dose of $60 \mathrm{mg}$ codeine phosphate generated a false-positive CEDIA buprenorphine result. The concentration of codeine in this sample was $2,550 \mathrm{ng} / \mathrm{mL}$. Codeine, morphine, and their respective metabolites were present in most of the false-positive patient urine samples. Raising the cutoff of the CEDIA buprenorphine assay from $5 \mathrm{ng} / \mathrm{mL}$ to $11.2 \mathrm{ng} / \mathrm{mL}$ decreased the risk of false-positive results, with only a modest increase in false-negative results giving both acceptable sensitivity and specificity.

\section{Strengths and limitations}

Cross-reactivity in the CEDIA buprenorphine assay has been described previously through experiments with spiked samples and in clinical case reports of false-positive urine samples. ${ }^{5,9}$ In the present study, cross-reactivity was assessed in a drug-naïve person and in a large patient material

Table 3 Results from CEDIA and HPLC-MS/MS in 25 urine samples with false-positive CEDIA buprenorphine

\begin{tabular}{|c|c|c|c|c|c|c|}
\hline \multirow{2}{*}{$\begin{array}{l}\text { CEDIA (ng/mL) } \\
\text { Buprenorphine }\end{array}$} & \multicolumn{6}{|c|}{ HPLC-MS/MS (ng/mL) } \\
\hline & C6G & Codeine & Norcodeine & Morphine & M3G & M6G \\
\hline 18.20 & 91,294 & $|3,56|$ & 4,166 & 200 & 3,138 & 646 \\
\hline 18.10 & 17,165 & 1,018 & 788 & 26 & 784 & 185 \\
\hline 16.70 & 0 & 0 & 0 & 0 & 0 & 0 \\
\hline 15.00 & 41,938 & 5,149 & $1,|2|$ & 57 & 2,538 & 600 \\
\hline 11.20 & 9,415 & 2,335 & 1,070 & 37,665 & 139,823 & 48,915 \\
\hline 10.60 & 11,602 & 3,832 & 970 & 27,621 & 178,586 & 68,758 \\
\hline 9.60 & $\mathrm{II}, 174$ & $\mathrm{I}, 766$ & 143 & 36,253 & 120,903 & 46,146 \\
\hline 8.60 & 0 & 0 & 0 & 0 & 0 & 0 \\
\hline 7.60 & 4,279 & $\mathrm{I}, 467$ & 51 & 29,390 & 125,056 & 48,454 \\
\hline 7.30 & 4,336 & 1,168 & 94 & 23,826 & 127,825 & 42,778 \\
\hline 7.10 & 37,801 & 2,096 & 1,067 & 29 & 2,123 & 415 \\
\hline 7.10 & 12,172 & 2,604 & 1,104 & 14,096 & 148,129 & 46,608 \\
\hline 6.90 & $29,86 I$ & 3,682 & 705 & 314 & 9,137 & $|, 66|$ \\
\hline 6.90 & 0 & 0 & 0 & 0 & 0 & 0 \\
\hline 6.80 & 24,820 & I,736 & 297 & 19,118 & 117,673 & 40,609 \\
\hline 6.80 & 0 & 0 & 0 & 0 & 0 & 0 \\
\hline 6.30 & 2,948 & $\mathrm{I}, 078$ & 86 & $|2,44|$ & 97,368 & 20,997 \\
\hline 6.30 & 0 & 0 & 0 & 0 & 0 & 0 \\
\hline 6.20 & 30,479 & 5,868 & 962 & 86 & $\mathrm{I}, 154$ & 231 \\
\hline 6.00 & 0 & 0 & 0 & 0 & 0 & 0 \\
\hline 5.90 & 8,464 & $\mathrm{I}, 527$ & 611 & 9,245 & 105,213 & 31,656 \\
\hline 5.80 & 27,626 & 1,676 & 1,273 & 57 & 3,092 & 461 \\
\hline 5.40 & 19,020 & I,078 & 514 & 17 & 3,461 & 600 \\
\hline 5.20 & 6,419 & I, 197 & 254 & 8,389 & 108,444 & 23,073 \\
\hline 5.00 & 0 & 0 & 0 & 0 & 0 & 0 \\
\hline
\end{tabular}

Abbreviations: CEDIA, cloned enzyme donor immunoassay; HPLC-MS/MS, high-performance liquid chromatography-tandem mass spectrometry; C6G, codeine-6glucuronide; M3G, morphine-3-glucuronide; M6G, morphine-6-glucuronide. 


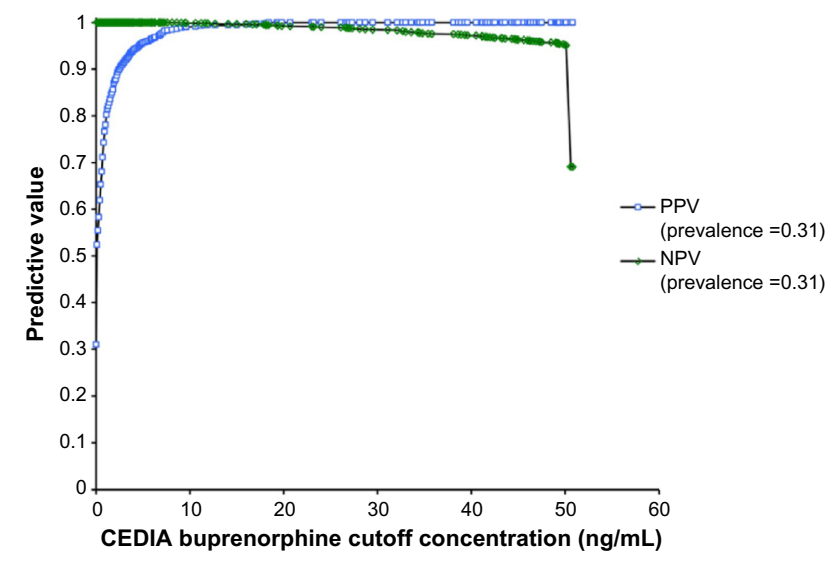

Figure I PPV and NPV with different cutoff concentrations of CEDIA for buprenorphine in patient urine samples $(n=2,272)$.

Abbreviations: PPV, positive predictive value; NPV, negative predictive value; CEDIA, cloned enzyme donor immunoassay.

associated with drug abuse. Importantly, our results demonstrate that false-positive results in the CEDIA buprenorphine assay can occur after intake of a low dose of codeine by a person not associated with drug abuse. By using a known drug-naïve person, we minimized the risk of other possible cross-reactants that could cause a false-positive buprenorphine assay. We cannot completely rule out that paracetamol or its metabolites could cross-react with the CEDIA buprenorphine assay. Paracetamol is found on the negative list in the CEDIA buprenorphine assays crossreactivity guide, tested in a concentration of $500,000 \mathrm{ng} / \mathrm{mL} .{ }^{9}$ Considering that the chemical structure is quite different from buprenorphine, significant cross-reactivity with paracetamol is unlikely.

The patient samples in our study are representative for the target population of our drugs-of-abuse screening panel. This is illustrated by the high prevalence of positive results for several drugs-of-abuse. Our study results may demonstrate the magnitude of false-positive buprenorphine samples in a typical population for the use of drugs-of-abuse assays and as such represent a complement to cross-reactivity data supplied by the manufacturer. The presented data are generated from samples collected in a naturalistic setting with limited access to structured detailed information, including drug abuse pattern, treatment modalities, or the presence of other diseases. Hence, differences in cross-reactivity between subgroups within this population could not be addressed. In particular, our study is limited by the fact that we do not have a complete drug subscription status of the patients. We therefore do not know whether substances other than the analyzed drugs-of-abuse could be present in urine samples, causing false-positive
CEDIA buprenorphine. For instance, in one case report, the antipsychotic amisulpride caused cross-reactivity with buprenorphine. ${ }^{15}$ In addition, our HPLC-MS/MS method only detects known analytes and has no screening option for other structurally related substances.

\section{Possible cross-reactants}

The manufacturer's cross-reactivity guide serves to evaluate unexpected positive result in the CEDIA buprenorphine assay. According to this guide, the lowest concentration of codeine that yielded a false-positive result for buprenorphine was $34,000 \mathrm{ng} / \mathrm{mL}$. This is in accordance with the data from spiked samples in other studies. ${ }^{5,11}$ In our study, the codeine concentrations associated with false-positive CEDIA buprenorphine were considerably lower, in the range of 1,000-13,500 $\mathrm{ng} / \mathrm{mL}$. This indicates that codeine alone did not cause the false-positive results. In the 18 samples with codeine, we also detected either codeine metabolites or other opioids and their metabolites. In our case study, the sample with a false-positive buprenorphine result had a concentration of $490 \mathrm{ng} / \mathrm{mL}$ and $38,467 \mathrm{ng} / \mathrm{mL}$ of norcodeine and $\mathrm{C} 6 \mathrm{G}$, respectively, in addition to codeine at a concentration of $2,550 \mathrm{ng} / \mathrm{mL}$. One of the patient samples in the performance study contained C6G in a concentration $>50,000 \mathrm{ng} / \mathrm{mL}$. Several samples contained $\mathrm{C} 6 \mathrm{G}$ in concentrations between $20,000 \mathrm{ng} / \mathrm{mL}$ and $50,000 \mathrm{ng} / \mathrm{mL}$, concentrations that may have contributed to a false-positive buprenorphine result. These data are in accordance with data from Böttcher and Beck who demonstrated that $\mathrm{C} 6 \mathrm{G}$ in a concentration of $50,000 \mathrm{ng} / \mathrm{mL}$ gave a result around the CEDIA buprenorphine cutoff of $5 \mathrm{ng} / \mathrm{mL}$. ${ }^{5}$ To confirm these findings, we spiked negative urine samples with $\mathrm{C} 6 \mathrm{G}$ and found that a concentration of $40,000 \mathrm{ng} / \mathrm{mL}$ yielded a signal corresponding to $6.2 \mathrm{ng} /$ $\mathrm{mL}$ in the CEDIA buprenorphine assay.

Norcodeine concentrations were low $(<4,200 \mathrm{ng} / \mathrm{mL})$ in urine samples, which were false positive for buprenorphine. The manufacturer's cross-reactivity guide did not evaluate norcodeine, but cross-reactivity with the CEDIA buprenorphine assay has been demonstrated when norcodeine concentrations were $100,000 \mathrm{ng} / \mathrm{mL} .{ }^{5}$ Based on these data, the contribution of norcodeine to the overall cross-reactivity in our study population is probably negligible.

Some of the false-positive patient samples also contained morphine, M3G, morphine-6-glucuronide (M6G) in high enough concentrations to contribute to cross-reactivity. In a study where urine samples were spiked with different opioids, they showed cross-reactivity in the CEDIA buprenorphine assay for all the tested opioids. ${ }^{11}$ In a sample spiked with a 
combination of dihydrocodeine and several metabolites of dihydrocodeine, in concentrations lower than what should give significant cross-reactivity for each substance alone, CEDIA yielded a positive buprenorphine result, indicating additive interference. We therefore suggest that a sum of structurally related compounds yielded a response above cutoff in the CEDIA buprenorphine assay in most of the false-positive samples in our study, although the concentration of each of them separately was lower than what is shown to give cross-reactivity in spiked samples.

In seven of the samples with false-positive CEDIA buprenorphine, no codeine, morphine, or their metabolites were detected with our HPLC-MS/MS method. Methadone was detected in five of these samples, oxazepam in two, and delta9-tetrahydrocannabinol and zopiclone in one. Methadone was the only detected substance in two of the five false-positive samples. Methadone concentrations $>320,000 \mathrm{ng} / \mathrm{mL}$ have been shown to give significant cross-reactivity in the CEDIA buprenorphine assay. ${ }^{11}$ The methadone concentrations in these two samples and the other methadone-positive samples in our study material were considerably lower (all $<53,000 \mathrm{ng} / \mathrm{mL}$ ). Oxazepam, delta-9-tetrahydrocannabinol, and zopiclone are structurally unrelated to opioids and are not known to cross-react with the CEDIA buprenorphine assay according to the manufacturer's guide. ${ }^{9}$ Although we cannot rule out that these drugs could have contributed to a false-positive buprenorphine result, these seven samples may have contained known cross-reactants that we did not analyze for, such as amisulpride and quetiapine. ${ }^{9}$

\section{Urine codeine concentration}

Codeine is reported to have interindividual pharmacokinetic variability, ${ }^{16}$ and it is therefore relevant to compare the urinary concentrations in the case study with results from previous published codeine elimination studies. In our case study, 5 hours after the administration of $60 \mathrm{mg}$ of codeine phosphate, the CEDIA buprenorphine assay produced a response $>5 \mathrm{ng} / \mathrm{mL}$ cutoff. The corresponding urine codeine concentration, as measured by HPLC-MS/MS, was $2,550 \mathrm{ng} / \mathrm{mL}$. This codeine concentration is somewhat lower than the concentrations from a previous study in which the pattern of codeine and metabolites in urine was examined in five patients after the intake of $30 \mathrm{mg}$ of codeine. ${ }^{17}$ In that study, the urinary concentrations of codeine were ranging from $5,000 \mathrm{ng} / \mathrm{mL}$ to $20,000 \mathrm{ng} / \mathrm{mL} 12$ hours after ingestion. In another study, four healthy volunteers were given $30 \mathrm{mg}$ codeine phosphate. Codeine was detectable in urine from 1 hour to 24 hours, with a maximum excretion rate after 2 hours. The highest concentrations were between $5,100 \mathrm{ng} / \mathrm{mL}$ and $13,300 \mathrm{ng} / \mathrm{mL}$. Concentrations after 4 hours and 6 hours ranged from $500 \mathrm{ng} / \mathrm{mL}$ to $5,500 \mathrm{ng} / \mathrm{mL} .{ }^{18}$ These data are in accordance with the results from our case study and strongly emphasize the clinical significance of crossreactivity in the CEDIA buprenorphine assay even after intake of therapeutic doses of codeine.

Codeine is mainly metabolized by glucuronidation to C6G. The amount of C6G may vary by ethnicity. ${ }^{16}$ Genetic variability in the activity of CYP2D6 does primarily affect the demethylation of codeine to morphine and norcodeine and to a lesser extent the glucuronidation to $\mathrm{C} 6 \mathrm{G} .{ }^{19}$ It is possible that genetic factors that contribute to variations in metabolite concentrations are of importance for the generation of false-positive CEDIA buprenorphine results after intake of therapeutic codeine doses. Future research may contribute to elucidate this question.

\section{Implications}

If all urine samples positive for CEDIA buprenorphine were routinely analyzed also by a more specific method, such as HPLC-MS/MS, false-positive results would have been detected. Then, the recommended cutoff from the producer could be adequate, although the ROC analysis indicates that a higher cutoff would give a better accuracy in our population. Most buprenorphine-positive CEDIA samples, however, are not analyzed with HPLC-MS/MS in our laboratory, which is also common routine in several other laboratories in Norway. With the CEDIA buprenorphine assay, we have experienced that the clinicians may not question the assay results and may react also to false-positive samples with therapeutic means. These reactions include exclusion from drug abuse treatment institutions, more rigid treatment plans, and more frequent urine sample controls. In addition, false-positive samples could harm the doctor-patient relationship, giving both the doctor and the patient reason to lose confidence in each other. Therefore, we recommend increasing the cutoff for the CEDIA buprenorphine assay and propose $10 \mathrm{ng} / \mathrm{mL}$ for all practical reasons. Study results show that the higher cutoff does not completely remove the risk of false-positive samples. Clinicians should therefore be informed about the possible cross-reactivity and be encouraged to require a more specific analytical method in cases with unexpected positive CEDIA buprenorphine results. Still, a higher cutoff substantially diminishes the risk of false-positive samples caused both by codeine and its metabolites and other opioids, and thereby the risk of erroneous clinical interpretations. 


\section{Conclusion}

Cross-reactivity in the CEDIA buprenorphine assay was seen even after intake of therapeutic doses of codeine phosphate. Metabolites of codeine and morphine may contribute to the cross-reactivity in urine samples from patients with drug abuse. The CEDIA buprenorphine cutoff concentration should be raised when the assay is used in a therapeutic setting without confirmatory analyses. Furthermore, clinicians should be well informed about the risk of false-positive results with the CEDIA buprenorphine assay.

\section{Disclosure}

The authors report no conflicts of interest in this work.

\section{References}

1. Moody DE. Metabolic and toxicological considerations of the opioid replacement therapy and analgesic drugs: methadone and buprenorphine. Expert Opin Drug Metab Toxicol. 2013;9(6):675-697.

2. EMCDDA. European Drug Report 2014: Trends and Developments. Available from: http://www.emcdda.europa.eu/publications/edr/trendsdevelopments/2014. Accessed April 19, 2015.

3. Yokell MA, Zaller ND, Green TC, Rich JD. Buprenorphine and buprenorphine/naloxone diversion, misuse, and illicit use: an international review. Curr Drug Abuse Rev. 2011;4(1):28-41.

4. Atluri S, Sudarshan G, Manchikanti L. Assessment of the trends in medical use and misuse of opioid analgesics from 2004 to 2011. Pain Physician. 2014;17(2):E119-E128.

5. Böttcher M, Beck O. Evaluation of buprenorphine CEDIA assay versus GC-MS and ELISA using urine samples from patients in substitution treatment. J Anal Toxicol. 2005;29(8):769-776.

6. Saleh A, Stephanson NN, Granelli I, Villén T, Beck O. Evaluation of a direct high-capacity target screening approach for urine drug testing using liquid chromatography-time-of-flight mass spectrometry. J Chromatogr B Analyt Technol Biomed Life Sci. 2012;909:6-13.

7. George S. Position of immunological techniques in screening in clinical toxicology. Clin Chem Lab Med. 2004;42(11):1288-1309.

8. Saitman A, Park HD, Fitzgerald RL. False-positive interferences of common urine drug screen immunoassays: a review. J Anal Toxicol. 2014;38(7):387-396.
9. Thermo Fisher Scientific. Drugs of Abuse Cross-Reactivity Guide, CEDIA Buprenorphine $5 \mathrm{ng} / \mathrm{mL}$ Cutoff. Thermo Fisher Scientific, Clinical Diagnostics, Fremont; 2013. Available from: http://www. thermoscientific.com/content/dam/tfs/SDG/CDD/CDD\%20Documents/ Product $\% 20$ Manuals\%20\&\%20Specifications/Diagnostic\%20Testing \%20Reagents/Drug\%20of\%20Abuse\%20Testing\%20(DAT)\%20 Calibrators\%20Controls\%20and\%20Reagents/Drug\%20of\%20 Abuse\%20Reagents/CEDIA-Buprenorphine-5ng-mL-CRG-R14.pdf. Accessed April 19, 2015.

10. Melanson SE, Snyder ML, Jarolim P, Flood JG. A new highly specific buprenorphine immunoassay for monitoring buprenorphine compliance and abuse. J Anal Toxicol. 2012;36(3):201-206.

11. Pavlic M, Libiseller K, Grubwieser P, Rabl W. Cross-reactivity of the CEDIA buprenorphine assay with opiates: an Austrian phenomenon? Int J Legal Med. 2005;119(6):378-381.

12. Hull MJ, Bierer MF, Griggs DA, Long WH, Nixon AL, Flood JG. Urinary buprenorphine concentrations in patients treated with suboxone as determined by liquid chromatography-mass spectrometry and CEDIA immunoassay. J Anal Toxicol. 2008;32(7):516-521.

13. European Union. Official Journal of the European Communities; 2002; L 221/8. Available from: http://eur-lex.europa.eu/LexUriServ/ LexUriServ.do?uri=OJ:L:2002:221:0008:0036:EN:PDF.

14. Ferrara SD, Tedeschi L, Frison G, et al. Drugs-of-abuse testing in urine: statistical approach and experimental comparison of immunochemical and chromatographic techniques. J Anal Toxicol. 1994;18(5): 278-291.

15. Birch MA, Couchman L, Pietromartire S, et al. False-positive buprenorphine by CEDIA in patients prescribed amisulpride or sulpiride. J Anal Toxicol. 2013;37(4):233-236.

16. Yue QY, Svensson JO, Alm C, Sjöqvist F, Säwe J. Interindividual and interethnic differences in the demethylation and glucuronidation of codeine. Br J Clin Pharmacol. 1989;28(6):629-637.

17. Posey BL, Kimble SN. High-performance liquid chromatographic study of codeine, norcodeine, and morphine as indicators of codeine ingestion. J Anal Toxicol. 1984;8(2):68-74.

18. Delbeke FT, Debackere M. Urinary concentrations of codeine and morphine after the administration of different codeine preparations in relation to doping analysis. J Pharm Biomed Anal. 1991;9(10-12): 959-964.

19. Yue QY, Hasselström J, Svensson JO, Säwe J. Pharmacokinetics of codeine and its metabolites in Caucasian healthy volunteers: comparisons between extensive and poor hydroxylators of debrisoquine. Br J Clin Pharmacol. 1991;31(6):635-642. 


\section{Supplementary material}

Table SI Analytical performance of HPLC-MS/MS for relevant analytes

\begin{tabular}{|c|c|c|c|}
\hline Component & Calibration range $^{a}$ & Limit of detection $^{\mathrm{a}}$ & Imprecision ${ }^{\mathrm{b}}(\%)$ \\
\hline 6-Monoacetylmorphine & $33-3,275$ & 6.0 & 10.5 \\
\hline 7-Aminoclonazepam & $29-5,737$ & 2.33 & 6.7 \\
\hline 7-Aminoflunitrazepam & $28-5,690$ & 2.25 & 6.8 \\
\hline 7-Aminonitrazepam & $25-5,031$ & 0.7 & 15.3 \\
\hline Alprazolam & $31-6,178$ & 0.9 & 5.1 \\
\hline Amphetamine & $27-2,708$ & 4.4 & 11.7 \\
\hline Benzoylecgonine & $29-2,894$ & 0.3 & 5.8 \\
\hline Cocaine & $6-608$ & 0.2 & 12.0 \\
\hline Codeine & $30-2,997$ & 6.9 & 16.3 \\
\hline Codeine-6-glucuronide & $95-9,511$ & 5.0 & 15.3 \\
\hline Desmethyldiazepam & $54-10,832$ & 3.5 & 5.1 \\
\hline Diazepam & $3-570$ & 1.9 & 10.4 \\
\hline EDDP & $28-2,775$ & 0.8 & 29.1 \\
\hline Ephedrine & $33-3,320$ & 5.5 & 13.6 \\
\hline Ethylmorphine & $31-3,137$ & 7.7 & 13.4 \\
\hline Hydrocodone & $60-5,994$ & 10.9 & 17.6 \\
\hline MDA & $36-3,589$ & 3.3 & 9.8 \\
\hline MDMA & $39-3,873$ & 1.0 & 10.7 \\
\hline Methadone & $31-3,102$ & 1.4 & 32.0 \\
\hline Methamphetamine & $30-2,992$ & 5.8 & 8.2 \\
\hline Morphine & $29-2,855$ & 9.0 & 17.1 \\
\hline Morphine-3-glucuronide & $23 \mathrm{I}-23,074$ & 8.1 & 6.7 \\
\hline Morphine-6-glucuronide & $|39-| 3,85 \mid$ & 15.0 & 8.5 \\
\hline $\mathrm{N}$-desmethylzopiclone & $38-7,5 \mid 3$ & 2.6 & 7.5 \\
\hline Norcodeine & $29-2,880$ & 8.8 & 20.2 \\
\hline Oxazepam & $57-11,470$ & 4.4 & 7.5 \\
\hline Oxycodone & $63-6,313$ & 7.2 & 10.1 \\
\hline Temazepam & $60-12,069$ & 2.6 & 4.8 \\
\hline Zopiclone- $\mathrm{N}$-oxide & $4 I-8,122$ & 1.5 & 11.3 \\
\hline
\end{tabular}

Notes: a Concentrations are given in $\mathrm{ng} / \mathrm{mL}$; botal analytical imprecision is calculated based on performance at lowest calibrator plus $25 \%$.

Abbreviations: HPLC-MS/MS, high-performance liquid chromatography-tandem mass spectrometry; EDDP, 2-ethylidene-1,5-dimethyl-3,3-diphenylpyrrolidine; MDA, 3,4-methylenedioxy-amphetamine; MDMA, 3,4-methylenedioxy-methamphetamine.

\section{Publish your work in this journal}

Substance Abuse and Rehabilitation is an international, peer-reviewed, open access journal publishing original research, case reports, editorials, reviews and commentaries on all areas of addiction and substance abuse and options for treatment and rehabilitation. The manuscript management system is completely online and includes a very quick and fair

\section{Dovepress}

peer-review system. Visit http://www.dovepress.com/testimonials.php to read real quotes from published authors. 